\title{
Immunologic burden links periodontitis to acute coronary syndrome
}

\author{
Liljestrand, John M.
}

2018-01

Liljestrand , J M , Paju , S, Pietiäinen , M , Buhlin , K , Persson , G R , Nieminen , M S , Sinisalo , J , Mäntylä , P \& Pussinen , P J 2018 , ' Immunologic burden links periodontitis to acute coronary syndrome ' , Atherosclerosis , vol. 268 , pp. 177-184 . https://doi.org/10.1016/j.atherosclerosis.2017.

http://hdl.handle.net/10138/298558

https://doi.org/10.1016/j.atherosclerosis.2017.12.007

publishedVersion

Downloaded from Helda, University of Helsinki institutional repository.

This is an electronic reprint of the original article.

This reprint may differ from the original in pagination and typographic detail.

Please cite the original version. 


\title{
Immunologic burden links periodontitis to acute coronary syndrome
}

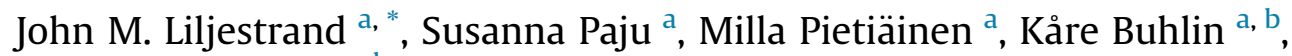 \\ G. Rutger Persson ${ }^{\text {c, d, }}$, Markku S. Nieminen ${ }^{\mathrm{e}}$, Juha Sinisalo ${ }^{\mathrm{e}}$, Päivi Mäntylä ${ }^{\mathrm{a}, \mathrm{f}}$, \\ Pirkko J. Pussinen ${ }^{\text {a }}$ \\ a Oral and Maxillofacial Diseases, University of Helsinki and Helsinki University Hospital, Haartmaninkatu 8, 00290, Helsinki, Finland \\ ${ }^{\mathrm{b}}$ Division of Periodontology, Department of Dental Medicine, Karolinska Institutet, Huddinge, Sweden \\ ${ }^{\mathrm{c}}$ Department of Oral Medicine, University of Washington, Seattle, WA, USA \\ d Department of Periodontics, University of Washington, Seattle, WA, USA \\ e Department of Cardiology, Heart and Lung Center, Department of Medicine, Helsinki University Hospital, Helsinki, Finland \\ ${ }^{\mathrm{f}}$ Institute of Dentistry, University of Eastern Finland, Kuopio, Finland
}

\section{A R T I C L E I N F O}

\section{Article history:}

Received 3 August 2017

Received in revised form

10 November 2017

Accepted 5 December 2017

Available online 6 December 2017

\section{Keywords:}

Periodontitis

Cardiovascular diseases

Acute coronary syndrome

Antibodies

Enzyme-linked immunosorbent assay

Molecular mimicry

Bacteria

\begin{abstract}
A B S T R A C T
Background and aims: Periodontitis, a common polymicrobial inflammatory disease in the tooth supporting tissues, is a risk factor for coronary artery disease. One of the proposed underlying mechanisms is the systemic immune response to periodontal infection. We studied how serum antibodies against seven periodontal pathogens and their subgingival levels associate with each other, periodontitis, and coronary artery disease.

Methods: The Parogene cohort included 505 Finnish patients (mean age 63 y) who underwent coronary angiography, and clinical and radiographic oral examinations. Coronary diagnosis was defined as no significant coronary artery disease $(<50 \%$ stenosis, $n=152)$, stable coronary artery disease $(\geq 50 \%$ stenosis, $\mathrm{n}=184)$ and acute coronary syndrome $(\mathrm{n}=169)$. Levels of subgingival Aggregatibacter actinomycetemcomitans, Porphyromonas gingivalis, Porphyromonas endodontalis, Prevotella intermedia, Tannerella forsythia, Campylobacter rectus, and Fusobacterium nucleatum were determined by checkerboard DNA-DNA hybridization. Serum antibody (IgA/IgG) levels were analyzed with enzyme-linked immunosorbent assay (ELISA). Aggregate IgA/IgG burdens were calculated by summing and standardizing the serum antibody levels.

Results: Patients with active periodontitis were characterized by higher levels of subgingival bacteria and corresponding IgA/IgG response. Quartiles 2-4 of serum IgA/IgG burden indicated higher risk for acute coronary syndrome (OR 1.84, 95\%CI 1.01-3.35 for IgA; OR 1.87, 95\%CI 1.01-3.46 for IgG) independently of established cardiovascular risk factors, body mass index, number of teeth, subgingival bacterial levels and periodontal diagnosis.

Conclusions: Our findings support the hypothesis that the association between periodontitis and cardiovascular diseases is partly mediated by the immunologic response for periodontal pathogens.
\end{abstract}

(C) 2017 Elsevier B.V. All rights reserved.

\section{Introduction}

Periodontitis is a chronic inflammatory disease in the tooth supporting tissues. It is one of the most common diseases worldwide; the severe form has a global age-standardized prevalence of $11.2 \%$ [1]. Periodontitis is preceded by gingivitis, and progresses as a

\footnotetext{
* Corresponding author. Oral and Maxillofacial Diseases, University of Helsinki, Biomedicum Helsinki 1, Haartmaninkatu 8, P.O.Box 63, FI-00014, Helsinki, Finland. E-mail address: john.liljestrand@helsinki.fi (J.M. Liljestrand).
}

complex interplay between putative periodontal pathogens and host response in susceptible individuals. If left untreated, the resulting resorption of alveolar bone leads to increased tooth mobility and eventually loss of teeth [2]. The deleterious effects of periodontitis are, however, not restricted to the oral cavity. Periodontitis may cause bacteremia, endotoxemia, and systemic low grade inflammation [3].

Even though periodontitis has been regarded as a polymicrobial infection for a century, the exact influence of periodontal pathogens is still under research. Some species, such as Aggregatibacter actinomycetemcomitans, Porphyromonas gingivalis, Prevotella 
intermedia, Tannerella forsythia, Campylobacter rectus and Fusobacterium nucleatum form complexes that associate with each other in a virulent manner, and are traditionally considered as periodontal pathogens [4]. The development of sequencing techniques has enabled identification of new putative periodontal pathogens. Porphyromonas endodontalis is one of the proposed candidates with a moderate grade of evidence [5]. The emerging concept of periodontal pathogenesis emphasizes the role of polymicrobial synergy caused by keystone pathogens and dysbiosis in the subgingival biofilm community [6].

The confounder independent association between periodontitis and atherosclerotic vascular disease is widely recognized and consistent through diverse populations $[7,8]$. One of the mechanistic explanations is the activation of adaptive immunity towards invasive periodontal pathogens, resulting in molecular mimicry by cross-reactive T, or B lymphocytes [9]. Several periodontal pathogens incorporate antigens, which share homology with human epitopes, and the resulting auto-reactive antibodies may induce endothelial dysfunction, systemic inflammation and promote atherogenesis $[3,10]$. These oral pathogens promote atherogenesis both directly, by virulence factors and endothelial invasion, which activates pro-atherogenic mechanisms, and via immunologic mechanisms, such as cross-activation between host- and pathogen antigens [11]. Therefore, high serum antibody levels to periodontal pathogens are likely to have both direct effects on the development of coronary artery disease (CAD) and simultaneously indicate periodontal infection [12]. From a clinical perspective, systemic antibody responses to periodontal pathogens have been proposed as surrogate markers for periodontitis [13-15].

It has been described repeatedly that cardiovascular risk associates with the inflammatory burden consisting of multiple microbial species [16-18]. Periodontitis is a polymicrobial disease, its pathogens share common surface antigens with the host, and some of the bacterial species have been associated with atherosclerosis. The relationships of the aggregate periodontal pathogen burden, their immune responses and CAD have not been reported before. We investigated these associations utilizing a well characterized population having angiographically verified coronary artery disease diagnosis as well as comprehensive clinical oral examinations with data on a select group of periodontal pathogens and serum antibody levels.

\section{Materials and methods}

\subsection{Population}

The Corogene cohort consists of 5297 Finnish patients who underwent coronary angiography between June 2006 and March 2008 at the Helsinki University Central Hospital as previously described [19]. A random gender-stratified subsample $(\mathrm{N}=505)$ was enrolled for extensive clinical, and radiographic oral examinations. These individuals constitute the Parogene cohort used in this study. The study complies with the principles of the Declaration of Helsinki and adheres to the STROBE guidelines for observational studies. Informed consent was obtained from all study subjects. The study design was approved by the Helsinki University Central Hospital ethics committee (approval reference number 106/ 2007).

\subsection{Examinations}

The oral examinations were performed by two calibrated periodontal specialists (PM and $\mathrm{KB}$ ) who were unaware of the coronary status. The data collection has been described in detail [20]. Among other parameters "bleeding on probing" (BOP) was registered as a proxy for active gingival inflammation [21]. Periodontal pocket probing depth (PPD) was measured from six sites on each tooth and number pockets with PPD $4-5 \mathrm{~mm}$ and PPD $\geq 6 \mathrm{~mm}$ were registered [20]. Periodontal inflammatory burden index was calculated by adding the number of periodontal pockets indicating mild to moderate periodontitis (PPD 4-5 mm) to the weighted number of periodontal pockets indicating more advanced periodontitis (number of periodontal pockets with PPD $\geq 6 \mathrm{~mm}$ multiplied by two) as previously reported $[20,22]$. This index takes into account the enlargement of inflamed subgingival surface area in deepened periodontal pockets. Alveolar bone loss $(\mathrm{ABL})$, a hallmark of periodontitis, and the number of teeth present were determined from panoramic radiographs. Periodontal diagnosis was defined as "healthy" (no ABL and BOP $<25 \%, n=46$ ), "gingivitis" (no ABL and $\mathrm{BOP} \geq 25 \%, n=65$ ), "history of periodontitis" (mild-severe ABL and $\mathrm{BOP}<25 \%, \mathrm{n}=92$ ) and "active periodontitis" (mild-severe $\mathrm{ABL}$, $\mathrm{BOP} \geq 25 \%, n=269$ ). These definitions for the periodontal diagnosis have been reported earlier [23]. Edentulous subjects $(n=33)$ lack periodontal diagnosis.

Subgingival bacterial samples were collected from the deepest periodontal pocket in each quadrant [24]. Bacterial levels of seven studied periodontal pathogens, A. actinomycetemcomitans, P. gingivalis, $P$. endodontalis, $P$. intermedia, T. forsythia, $C$. rectus and F. nucleatum, were analyzed with checkerboard DNA-DNA hybridization [25,26]. Bacterial prevalence was defined as level $>0$.

Information on weight, height and smoking was obtained from questionnaires. Subjects were considered having hypertension, dyslipidemia or diabetes mellitus if they had respective mediations. Coronary diagnosis was acquired from the coronary artery angiography, symptoms, and laboratory determinations as follows: no significant $\mathrm{CAD} /$ controls $(<50 \%$ stenosis, $\mathrm{n}=152$ ), stable CAD ( $\geq 50 \%$ stenosis, $n=184$ ), acute coronary syndrome (ACS; $\geq 50 \%$ stenosis, an episode of typical chest pain, and elevated levels of a cardiac biomarkers, $n=169$ ) [19]. Blood samples were drawn and stored at $-80 \mathrm{C}^{\circ}$.

Serum levels of immunoglobulin $A$ and $G(\operatorname{Ig} A / \operatorname{IgG})$ against whole cell antigen of all studied bacteria were determined with enzyme-linked immunosorbent assay (ELISA) [27]. When the antigen composed of several strains, the bacterial suspensions with aligned densities were mixed in equal volumes before coating the plates. The serum samples were analyzed as duplicates and two dilutions. The mean absorbance values from four wells were calculated and normalized per reference serum samples on each plate and used as a continuous variable [28,29]. A. actinomycetemcomitans and $P$. endodontalis $\operatorname{IgA} / \operatorname{IgG}$ determinations have been described earlier $[30,31]$ and the remaining laboratory analyses were performed for this study. The used bacterial strains (DNA-DNA hybridization/ELISA), ELISA dilutions and inter-assay coefficients of variations are displayed on Supplemental Table 1. We summed the levels of subgingival A. actinomycetemcomitans (two strains) and F. nucleatum (four strains) after controlling that the prevalence of any single strain does not affect the corresponding serum antibody response (nonsignificant in Mann-Whitney $\mathrm{U}$ and Students T- tests, data not shown).

\subsection{Statistical analyses}

The statistical analyses were performed with the SPSS statistics software (version 24; IBM Corp, Armonk, NY, USA). Comparison between groups was performed with the Mann-Whitney $U$ test (non-normal) for continuous variables and $\chi^{2}$ test for categorical variables. The levels of subgingival bacteria and their corresponding serum antibodies were standardized with Z-score prior to analysis to increase normality and to facilitate comparison between 
these continuous variables. Subgingival bacterial levels and serum IgA/IgG levels for the studied species were summed and standardized to acquire parameters that reflect the IgA/IgG burden.

The distributions of serum antibody-levels were visually inspected with population pyramid histograms, split by subgingival bacterial presence. The number of teeth present, periodontal inflammatory burden index, smoking and age were analyzed for potential interaction effects with factorial ANOVA, as these have been proposed as effect modifiers [32]. Associations between continuous variables were determined with a confounder adjusted linear regression model. Post hoc test with logistic regression models were performed for statistically significant associations.

\section{Results}

\subsection{Population characteristics}

Basic demographics and cardiovascular risk factors across the studied population $(\mathrm{N}=505)$ are displayed on Table 1 . Most of the population represent older adults, while $71 \%$ were over 60 years old (mean age 63.4, SD 9.1). Stable CAD and ACS were characterized by a higher proportion of male subjects, diabetes mellitus, hypertension, and dyslipidemia, compared to subjects without significant coronary stenosis. Periodontal disease was highly prevalent in the population; only $9 \%$ were periodontally healthy and $53 \%$ had active periodontitis. Edentulous subjects $(\mathrm{n}=33)$ are presented alongside true periodontal diagnoses, as they represent an end-point for oral diseases.

\subsection{Subgingival bacteria and immunological response}

We examined the association between subgingival prevalence of studied bacterial species (A. actinomycetemcomitans, P. gingivalis, P. endodontalis, P. intermedia, T. forsythia, C. rectus, F. nucleatum) and serum IgA and IgG levels to these species (Table 2). The serum antibody levels were generally higher for bacteria-positive subjects. However, the serum antibody levels had a high deviation and the differences were statistically significant only for $P$. gingivalis ( $\operatorname{Ig} A$ and $\operatorname{IgG})$, P. endodontalis (IgA and $\operatorname{IgG}$ ) and P. intermedia (IgG). All species were highly prevalent in the studied population (66-93\%). Population pyramid inspection revealed that a dominance of low serum antibody levels dilutes tests of significance, even though subjects with strong immunological response were generally positive for the corresponding bacteria. After controlling for interaction effects, we found that the positive association between subgingival T. forsythia prevalence and serum IgA was significant among never smokers, whereas $F$. nucleatum associated with IgG response among subjects below 65 years of age. The subgingival burden associated with serum antibody burden in a linear regression model adjusted for age, gender, smoking (never/ever) and number of teeth $(\mathrm{F}[5454]=9.666, p<0.001$ for $\operatorname{IgA}$ and $\mathrm{F}[5454]=9.299$, $p<0.001$ for $\operatorname{IgG})$.

\subsection{Periodontal status}

The groups of periodontal diagnoses were characterized by pocket probing depth measurements (number of pockets with PPD $4-5 \mathrm{~mm}$ or $\geq 6 \mathrm{~mm}$ ) and periodontal inflammatory burden index as continuous variables (Supplemental Fig. 1). Both history of periodontitis and active periodontitis were associated with higher pocket measures compared to periodontally healthy controls $(p<0.05)$. We examined the subgingival levels and corresponding serum IgA/IgG levels for all studied pathogens across diagnoses for periodontitis and edentulous subjects (Supplemental Table 2). Subgingival bacterial- and serum IgA/IgG burdens across groups of periodontal diagnoses are illustrated as error bars in Fig. 1, where all parameters were compared to periodontally healthy subjects. In general, periodontitis was associated with higher levels of subgingival bacteria and humoral immune response against them. Gingivitis associated significantly with higher levels of P. endodontalis and T. forsythia. History of periodontitis associated significantly with elevated immune response to $P$. gingivalis (IgA/ $\operatorname{IgG}), P$. endodontalis (IgA/IgG), P. intermedia (IgA) and combined serum antibody burden $(\operatorname{Ig} A / \operatorname{IgG})$. Active periodontitis associated significantly with elevated levels of A. actinomycetemcomitans (IgA/ $\operatorname{IgG}$ ), P. gingivalis (subgingival/IgA/IgG), P. endodontalis (subgingival/ IgA/IgG), P. intermedia (subgingival/IgA), T. forsythia (subgingival), C. rectus (subgingival), and subgingival/IgA/IgG burden. The findings were similar when adjusting for age, gender, and smoking in a multinomial logistic regression model (data not shown). In summary, both a history of periodontitis, and active periodontitis were characterized by higher immunological responses to seven studied

Table 1

Characteristics of subjects according to coronary status.

\begin{tabular}{|c|c|c|c|c|c|c|}
\hline & & No $C A D, n=152$ & Stable CAD, $\mathrm{n}=184$ & \multirow[b]{2}{*}{$p$-value ${ }^{a}$} & \multirow{2}{*}{$\frac{\text { ACS, } n=169}{\text { Mean }(S D)}$} & \multirow[b]{2}{*}{$p$-value ${ }^{a}$} \\
\hline & & \multicolumn{2}{|l|}{ Mean (SD) } & & & \\
\hline \multirow{3}{*}{$\begin{array}{l}\text { Age (years) } \\
\text { hs-CRP }\end{array}$} & & $61.2(9.2)$ & $65.5(8.2)$ & $<\mathbf{0 . 0 0 1}$ & $62.9(9.6)$ & 0.077 \\
\hline & & $6.6(13.3)$ & $4.1(7.9)$ & 0.002 & $19.3(35.5)$ & $<0.001$ \\
\hline & & $\mathrm{n}(\%)$ & & $p$-value ${ }^{\mathrm{b}}$ & $\mathrm{n}(\%)$ & $p$-value ${ }^{b}$ \\
\hline \multicolumn{2}{|l|}{ Gender (male) } & $70(46.1)$ & $136(73.9)$ & $<\mathbf{0 . 0 0 1}$ & $122(72.2)$ & $<0.001$ \\
\hline \multicolumn{2}{|l|}{ Diabetes mellitus } & $26(17.1)$ & $55(29.9)$ & 0.005 & 37 (21.9) & 0.294 \\
\hline \multicolumn{2}{|l|}{ Smoking (ever) } & $71(46.7)$ & $99(53.8)$ & 0.178 & $97(57.4)$ & 0.056 \\
\hline \multicolumn{2}{|l|}{ Hypertension } & $86(56.6)$ & $129(70.1)$ & 0.008 & $107(63.3)$ & 0.219 \\
\hline \multicolumn{2}{|l|}{ Dyslipidemia } & $107(70.4)$ & $172(93.5)$ & $<\mathbf{0 . 0 0 1}$ & $125(74.0)$ & 0.535 \\
\hline \multirow{2}{*}{\multicolumn{2}{|c|}{$\begin{array}{l}\text { Rheumatoid arthritis } \\
\text { Periodontal diagnosis }\end{array}$}} & $7(4.6)$ & $11(6.0)$ & 0.570 & $11(6.5)$ & 0.459 \\
\hline & Healthy & $18(11.8)$ & $14(7.6)$ & 0.044 & $14(8.3)$ & 0.175 \\
\hline \multirow{4}{*}{ Periodontal diagnosis } & Gingivitis & $28(18.4)$ & $16(8.7)$ & & $21(12.4)$ & \\
\hline & History of periodontitis & $27(17.8)$ & $42(22.8)$ & & $23(13.6)$ & \\
\hline & Active periodontitis & $70(46.1)$ & $100(54.3)$ & & $99(58.6)$ & \\
\hline & Edentulous & $9(5.9)$ & $12(6.5)$ & & $12(7.1)$ & \\
\hline
\end{tabular}

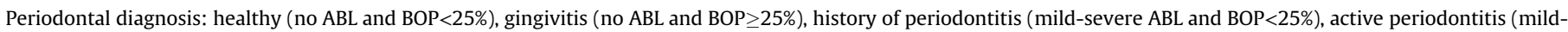
severe $A B L, B O P \geq 25 \%$, periodontal diagnosis not applicable for edentulous subjects. Statistically significant results $(p<0.05)$ are bolded. ACS, acute coronary syndrome; CAD, coronary artery disease; hs-CRP, high-sensitivity C-reactive protein.

a Mann-Whitney $U$ test.

b $\chi^{2}$ test; "No CAD" used as the reference. 
Table 2

Subgingival bacterial prevalence and corresponding serum antibodies.

\begin{tabular}{|c|c|c|c|c|}
\hline \multirow[t]{3}{*}{$\operatorname{Ig} A$} & \multicolumn{3}{|c|}{ Subgingival prevalence } & \multirow[t]{3}{*}{$p$-value ${ }^{a}$} \\
\hline & - & + & $\mathrm{n}(\%)$ prevalent & \\
\hline & \multicolumn{3}{|l|}{ Median (IQR) } & \\
\hline A. actinomycetemcomitans & $-0.14(0.98)$ & $-0.34(1.05)$ & $407(86)$ & 0.282 \\
\hline$P$. gingivalis & $-0.65(0.73)$ & $-0.39(1.44)$ & $380(80)$ & 0.014 \\
\hline P. endodontalis & $-0.53(0.89)$ & $-0.31(1.19)$ & $312(66)$ & 0.032 \\
\hline P. intermedia & $-0.24(1.08)$ & $-0.24(0.98)$ & $332(70)$ & 0.543 \\
\hline T. forsythia & $-0.27(0.91)$ & $-0.23(0.89)$ & $361(76)$ & 0.925 \\
\hline C. rectus & $-0.22(1.26)$ & $-0.20(1.15)$ & $396(83)$ & 0.612 \\
\hline F. nucleatum & $-0.35(0.85)$ & $-0.29(0.89)$ & $442(93)$ & 0.918 \\
\hline \multicolumn{5}{|l|}{$\operatorname{IgG}$} \\
\hline A. actinomycetemcomitans & $-0.26(1.15)$ & $-0.27(1.19)$ & $407(86)$ & 0.883 \\
\hline$P$. gingivalis & $-0.70(1.15)$ & $-0.17(1.78)$ & $380(80)$ & $<0.001$ \\
\hline P. endodontalis & $-0.39(1.19)$ & $-0.15(1.74)$ & $312(66)$ & 0.040 \\
\hline P. intermedia & $-0.34(0.98)$ & $-0.19(0.82)$ & $332(70)$ & 0.045 \\
\hline T. forsythia & $-0.25(1.34)$ & $-0.39(1.06)$ & $361(76)$ & 0.271 \\
\hline C. rectus & $-0.14(1.48)$ & $-0.14(1.25)$ & $396(83)$ & 0.703 \\
\hline F. nucleatum & $-0.37(0.92)$ & $-0.25(1.16)$ & 442 (93) & 0.304 \\
\hline
\end{tabular}

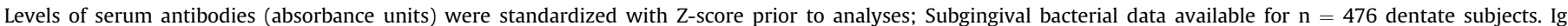
immunoglobulin. Statistically significant results $(p<0.05)$ are bolded.

a Mann-Whitney $U$ test.

periodontal pathogens. Only active periodontitis had simultaneously higher subgingival levels of corresponding bacteria.

\subsection{Coronary status}

Table 3 shows the levels of studied subgingival bacteria and their corresponding serum $\operatorname{IgA} / \operatorname{IgG}$ across groups of coronary diagnoses. Compared to subjects without significant coronary stenosis (reference), subjects with stable CAD had more subgingival $A$. actinomycetemcomitans and C. rectus -specific IgA. The immunological response was most evident for the group with ACS, who had significantly more A. actinomycetemcomitans (IgA/IgG), C. rectus (IgA), F. nucleatum (IgA) and IgA burden. Even a slight increase in IgA/IgG burden associated with ACS, and we performed post hoc analyses accordingly (Table 4). Quartiles 2-4 of IgA/IgG burden associated significantly with ACS in a logistic regression model adjusted with age, gender, smoking (never/ever), dyslipidemia, hypertension, diabetes mellitus, body mass index, and the number of teeth present (OR 1.98, 95\%CI 1.13-3.47, $p=0.017$ for IgA; OR $1.84,95 \%$ CI $1.04-3.23, p=0.035$ for $\operatorname{IgG}$ ). In further analyses, we added the subgingival burden and the periodontal diagnosis into the model as covariates. The subgingival burden had no significant association with ACS and the associations of quartiles 2-4 of IgA/ IgG burden with ACS hardly altered suggesting mediation of effects via immunologic response rather than confounding. No association was found between quartiles $2-4$ of $\operatorname{IgA} / \operatorname{IgG}$ burden and stable CAD.

\section{Discussion}

In this cross-sectional observational study, we found that subjects with a history of periodontitis had elevated levels of serum antibodies and subjects with active periodontitis had simultaneously high subgingival levels of the studied periodontal pathogens. Even slightly increased levels of serum $\operatorname{IgA} / \operatorname{IgG}$ burden associated with angiographically verified ACS. High levels of IgA indicate recent or repeated exposure of the antigen and our findings support the hypothesis that an active humoral immune response to typical periodontal pathogens has important systemic effects. Analyzing both antigens and antibodies in this wellcharacterized population makes this work novel.
Atherosclerosis is regarded as a common multifactorial "response to injury" in the vessel walls. Emerging evidence is linking bacterial infection to modulation of inflammation, a key element in all stages of atherogenesis, and initiation of arterial thrombosis, which causes acute coronary events [33]. A cellular adaptive immune response plays important modulatory effects on atherosclerosis, by activation of antigen-presenting cells, B- and Tlymphocytes [34]. Atherosclerosis is considered partly an inflammatory autoimmune disease, which might be triggered by binding of autoreactive antibodies to the vascular endothelial surface [11]. Periodontitis was highly prevalent in our population, all of whom had an initial indication for coronary angiography [19]. Periodontal pathogens are likely to affect atherogenesis locally, while they have frequently been found in atheromatous plaques [35]. The antibody production towards periodontal pathogens has been shown to auto-react with host antigens, and this molecular mimicry has been proposed to indirectly mediate the atherogenic effects of periodontitis $[3,36,37]$. The most studied periodontal pathogens in this regard are $A$. actinomycetemcomitans and $P$. gingivalis, for which several cross-reactive epitopes have been found [37,38]. Our ELISA assays are based on whole cell antigens, therefore all potential target epitopes, such as Hsp60, lipopolysaccharide and gingipain, are accounted for.

One of the major issues in past research on periodontitis and cardiovascular diseases has been the selection and heterogeneity of periodontal diagnosis [7]. Even though clinical and radiographic parameters have been widely used in studies on periodontitis and cardiovascular disease, microbiological measures and respective immune response have been proposed to better reflect the systemic burden of periodontitis [39]. This approach is in line with a systematic review and meta-analysis, which showed that systemic bacterial exposures are more pertinent in evaluation of atherosclerotic risk [40]. Moreover, our research group has previously reported a positive association between periodontitis-related serum antibodies and coronary outcomes in diverse populations [28,41-43]. The present study complements the hypothesis presented by Beck and coworkers, as serum antibodies to periodontal pathogens were stronger determinants for ACS than either periodontal diagnosis, or subgingival bacterial counts.

While several infectious agents have been linked to atherogenesis, it seems reasonable to simultaneously observe several 


\section{Subgingival microbial burden}

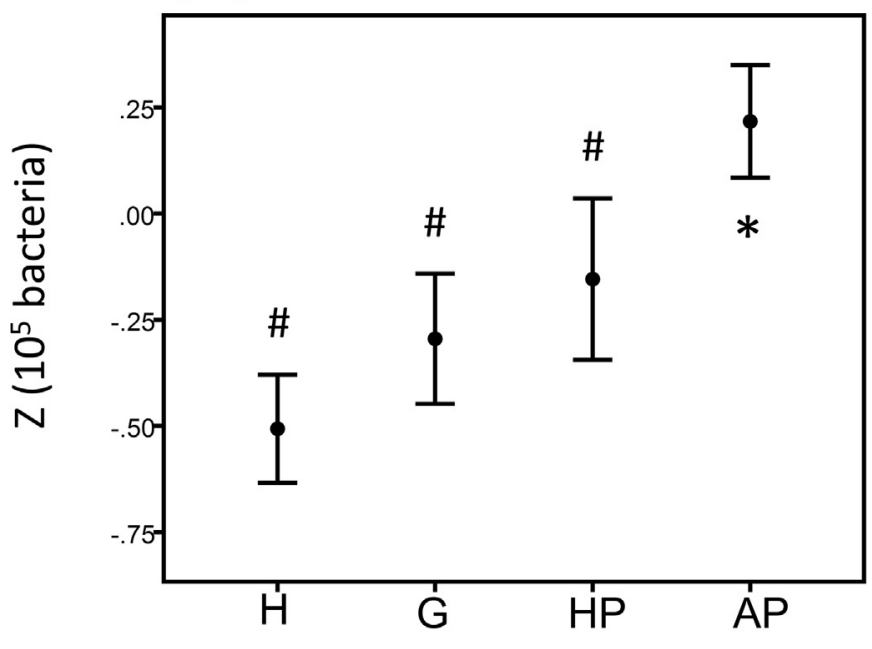

$\lg \mathrm{A}$ burden
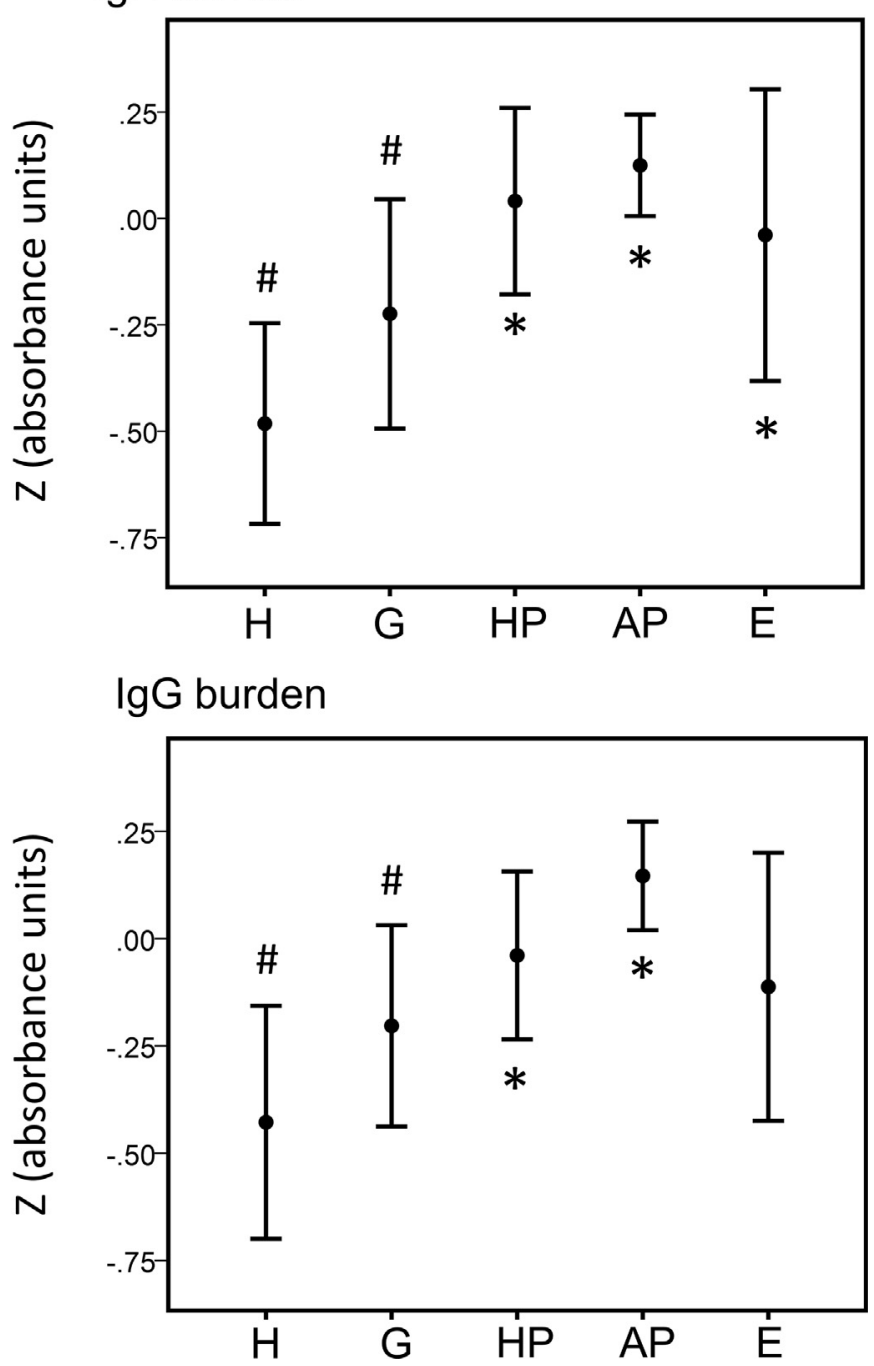

Fig. 1. Subgingival bacterial burden (x $10^{5}$ bacteria) for seven periodontal pathogens and immunological response (absorbance units) across groups of periodontal diagnosis (mean, 95\% CI)

Species-associated variables are summed and standardized. Diagnoses: healthy $(n=46)$, gingivitis $(n=65)$, history of periodontitis $(n=92)$, active periodontitis $(\mathrm{n}=269)$, edentulous $(\mathrm{n}=33)$. * Levels differ from $\mathrm{H}$; * levels differ from AP (MannWhitney $\mathrm{U}, p<0.05)$. species, rather than focusing on single ones [9]. The concept of "infectious burden" was first introduced by Zhu et al., who reported on an aggregated risk for CAD when the patients had simultaneous immune response to cytomegalovirus, Chlamydia pneumoniae, hepatitis A virus and herpes simplex virus [16]. Oral infectious burden and its immunologic response playing a part in the progression of CAD is widely accepted by the research community, although research is relatively scarce to date [44]. Beck et al. explored serum IgG levels specific for 17 periodontal microorganisms in $\mathrm{N}=4585$ adults and concluded that systemic exposure to oral organisms associates with subclinical atherosclerosis, and this association was intensified when several bacteria were grouped together [45]. In a much similar trend, Lund Håheim et al. showed that IgG antibodies to four common periodontal pathogens associates with self-reported myocardial infarction in multiadjusted analyses, but mainly when species were combined as in the "infectious burden" concept [46].

Many previous seroepidemiologic studies on periodontitis and CVD have been focused on IgG-antibodies whereas little is known about IgA response, which might better reflect the recent bacterial exposure due to shorter half-life time of this antibody. We have previously reported that $A$. actinomycetemcomitans- and $P$. gingivalis -specific serum IgA associates with myocardial infarction $[41,43]$. In a recent study by Boillot et al., systemic IgA levels to four periodontal pathogens showed no association with major cardiac events in a 1 year follow up of patients with prior myocardial infarction [47]. An inconclusive association has been reported for plasma IgG/IgA levels against four major periodontal pathogens and the extent of coronary atherosclerosis, coronary plaque vulnerability and coronary remodeling, although the sum of IgA levels had an inverse association with positive lesion remodeling [48]. Recently, Palm et al. showed that A. actinomycetemcomitans specific IgA levels associated with ischemic stroke, but testing the "infectious burden" hypothesis led to lost significance in the fully adjusted models [18]. The fact that IgA burden for seven periodontal pathogens associated with ACS in this study supports a positive dose-response relationship and warrants further research. Our study is distinguished by a broader view on periodontal microbes, as past investigations on immunologic burden are mostly focused on A. actinomycetemcomitans and $P$. gingivalis [10]. Taken together, a total infectious and immunologic burden seems to be a promising approach for evaluating cardiovascular risk, but several questions remain in the appropriate selection of antigens and methodology.

Our study setup stands out with simultaneous access to clinical and radiographic oral data, microbiological analyses on subgingival plaque, serological data on antibodies and precise angiographically verified coronary outcomes. In the statistical analyses, we have controlled for major cardiovascular confounders. The role of socioeconomic status as confounding factor is diminished, while all Finnish adults have the same prerequisites and access to adequate treatment. Autoantibody levels might be affected by sex hormones and menopause. This factor could not be controlled for in this study, as our female population was mainly post-menopausal. Our complementary analyses split by gender, suggested that the association between immunologic burden and ACS might be more apparent for women, a factor that we suggest should be taken into account in future studies.

Our study is cross sectional; hence, no conclusions of causality can be made. The definitions for periodontal diagnosis are published earlier [23]. But might differ from similar studies. Our study population is limited to those with a simultaneous indication for coronary angiography and capability to participate in thorough examinations. Therefore, selection- and Neyman's bias is evident and our cohort may not represent the general population, and our 
Table 3

Subgingival burden, serum antibodies, and cardiovascular diagnosis.

\begin{tabular}{|c|c|c|c|}
\hline \multirow[t]{2}{*}{ Subgingival burden } & No CAD $(n=138)$ & Stable CAD $(\mathrm{n}=168)$ & $\operatorname{ACS}(n=152)$ \\
\hline & \multicolumn{3}{|c|}{ Median (IQR) $p$-value ${ }^{a}$} \\
\hline A. actinomycetemcomitans & $-0.49(1.03)$ & $-0.30(1.18) 0.034$ & $-0.49(0.78) 0.980$ \\
\hline$P$. gingivalis & $-0.48(0.47)$ & $-0.47(0.60) 0.675$ & $-0.48(0.43) 0.795$ \\
\hline P. endodontalis & $-0.44(0.53)$ & $-0.43(0.54) 0.595$ & $-0.46(0.50) 0.398$ \\
\hline P. intermedia & $-0.34(0.80)$ & $-0.36(0.88) 0.340$ & $-0.38(0.90) 0.744$ \\
\hline T. forsythia & $-0.39(0.83)$ & $-0.35(1.25) 0.237$ & $-0.47(1.29) 0.793$ \\
\hline C. rectus & $-0.38(1.00)$ & $-0.35(0.91) 0.622$ & $-0.45(1.01) 0.737$ \\
\hline F. nucleatum & $-0.35(1.18)$ & $0.33(1.06) 0.816$ & $-0.44(1.04) 0.528$ \\
\hline Subgingival burden & $-0.31(1.28)$ & $-0.26(1.28) 0.375$ & $-0.47(1.36) 0.713$ \\
\hline \multicolumn{4}{|l|}{$\operatorname{IgA}$} \\
\hline A. actinomycetemcomitans & $-0.40(1.01)$ & $-0.34(1.13) 0.445$ & $-0.18(1.13) 0.002$ \\
\hline$P$. gingivalis & $-0.58(1.24)$ & $-0.45(1.44) 0.363$ & $-0.42(1.47) 0.070$ \\
\hline P. endodontalis & $-0.47(1.05)$ & -0.39 (1.17) 0.216 & $-0.33(1.05) 0.096$ \\
\hline P. intermedia & $-0.29(1.03)$ & $-0.23(1.19) 0.126$ & $-0.19(1.02) 0.153$ \\
\hline T. forsythia & $-0.35(0.93)$ & $-0.15(0.90) 0.061$ & $-0.29(0.83) 0.079$ \\
\hline C. rectus & $-0.32(1.19)$ & $-0.08(1.20) 0.009$ & $-0.19(1.16) 0.050$ \\
\hline F. nucleatum & $-0.44(0.99)$ & $0.30(0.81) 0.240$ & $-0.24(0.82) 0.009$ \\
\hline IgA burden & $-0.41(1.27)$ & -0.24 (1.19) 0.164 & $-0.05(1.19) 0.016$ \\
\hline \multicolumn{4}{|l|}{$\operatorname{IgG}$} \\
\hline A. actinomycetemcomitans & $-0.41(1.02)$ & $-0.24(1.26) 0.200$ & $-0.17(1.34) 0.043$ \\
\hline$P$. gingivalis & $-0.44(1.59)$ & $-0.31(1.79) 0.345$ & $-0.23(1.63) 0.168$ \\
\hline P. endodontalis & $-0.39(1.61)$ & $-0.11(1.72) 0.224$ & $-0.32(1.36) 0.659$ \\
\hline P. intermedia & $-0.26(0.93)$ & $-0.20(0.82) 0.885$ & $-0.17(1.05) 0.191$ \\
\hline T. forsythia & $-0.46(0.97)$ & $-0.26(1.07) 0.129$ & $-0.36(1.18) 0.182$ \\
\hline C. rectus & $-0.28(1.19)$ & $-0.02(1.45) 0.061$ & $0.14(1.19) 0.248$ \\
\hline F. nucleatum & $-0.26(1.15)$ & $-0.18(1.14) 0.510$ & $-0.34(1.17) 0.501$ \\
\hline IgG burden & $-0.37(1.78)$ & $-0.11(1.71) 0.194$ & $-0.04(1.43) 0.110$ \\
\hline
\end{tabular}

Levels of subgingival bacteria, serum antibodies (absorbance units) and their summed values were standardized with Z-score prior to analyses.

CAD, coronary artery disease; ACS, acute coronary syndrome; Ig, immunoglobulin.

a Mann-Whitney $U$ test with "No CAD" group used as reference; statistically significant results $(p<0.05)$ are bolded.

Table 4

Associations of IgA/IgG burden with cardiovascular diagnosis.

\begin{tabular}{|c|c|c|c|c|c|}
\hline \multirow[t]{2}{*}{ Antibody burden } & & \multicolumn{2}{|l|}{ Stable CAD } & \multicolumn{2}{|l|}{ ACS } \\
\hline & & OR (95\% CI) & $p$-value & OR (95\% CI) & $p$-value \\
\hline \multirow[t]{2}{*}{ IgA burden, $Q^{2-4}$} & Model 1 & $0.82(0.46-1.46)$ & 0.498 & $1.98(1.13-3.47)$ & 0.017 \\
\hline & Model 2 & $0.75(0.40-1.43)$ & 0.383 & $1.84(1.01-3.35)$ & 0.045 \\
\hline \multirow[t]{2}{*}{ IgG burden, $Q^{2-4}$} & Model 1 & $1.02(0.58-1.80)$ & 0.943 & $1.84(1.04-3.23)$ & 0.035 \\
\hline & Model 2 & $0.91(0.49-1.69)$ & 0.760 & $1.87(1.01-3.46)$ & 0.045 \\
\hline
\end{tabular}

Binomial logistic regression with "no $\mathrm{CAD}^{\prime \prime}$ used as reference.

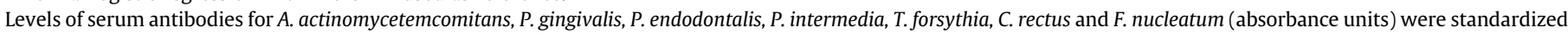

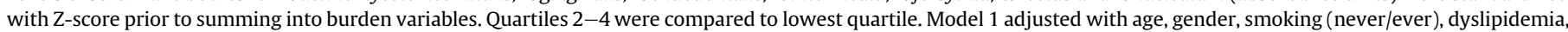

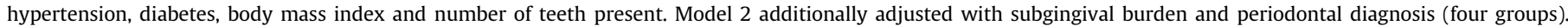
Statistically significant results $(p<0.05)$ are bolded.

CAD, coronary artery disease; ACS, acute coronary syndrome; Ig, immunoglobulin.

study population included several older adults. It has been previously noted that age is a significant effect modifier for associations between periodontitis and CVD [7], and that subgingival bacterial species elicit a stronger systemic immune response in younger individuals $[32,49,50]$, which might explain the modest associations observed in this study. Our method for assessing immunologic burden is somewhat crude and should therefore be interpreted with caution. Antibodies to periodontal pathogens elicit a "friend or foe" problem, as a normal immunologic response is essential for both progression and restriction of periodontal disease. In addition, a strong antibody response to periodontal pathogens might reflect the immune responsiveness of the host, which is considered a feature of CAD patients [11]. Therefore, the observed association might be dependent on host characteristics: patients who are susceptible to both periodontitis and CVD.

To conclude, we showed that periodontitis associates with elevated levels of serum IgA/IgG antibodies for A. actinomycetemcomitans, P. gingivalis, P. endodontalis, P. intermedia, T. forsythia, $C$. rectus and $F$. nucleatum. Patient with active periodontitis had simultaneously elevated subgingival microbial levels. Elevated serum antibody levels to these species were associated with ACS. The relationship between periodontitis and cardiovascular diseases might be partly mediated by the immunologic responses to periodontal pathogens. A combined antibody burden is a justified approach for evaluating this link, considering that periodontitis is a multifactorial infectious disease with several putative pathogens.

\section{Conflict of interest}

The authors declared they do not have anything to disclose regarding conflict of interest with respect to this manuscript.

\section{Financial support}

This study was supported by grants from the Finnish Dental Society Apollonia (JML), the Ida Montin foundation (JML), the Otto A. Malm foundation (JML), the Academy of Finland (1266053 to PJP; 
1296541 to SP), the Päivikki and Sakari Sohlberg foundation (to PJP), the Yrjö Jahnsson foundation (to PJP) and the Sigrid Juselius foundation (PJP).

\section{Author contributions}

Study conception and design: JML, SP, KB, MSN, JS, PM, PJP.

Acquisition of data: JML, KB, GRP, MSN, JS, PM.

Analysis and interpretation of data: JML, PM, PJP.

Manuscript drafting: JML.

Critical review and final approval: all authors.

\section{Acknowledgements}

We acknowledge Ms. Saija Perovuo for excellent technical assistance.

\section{Appendix A. Supplementary data}

Supplementary data related to this article can be found at https://doi.org/10.1016/j.atherosclerosis.2017.12.007.

\section{References}

[1] N.J. Kassebaum, E. Bernabe, M. Dahiya, B. Bhandari, C.J. Murray, et al., Globa burden of severe periodontitis in 1990-2010: a systematic review and metaregression, J. Dent. Res. 93 (2014) 1045-1053.

[2] D.F. Kinane, Causation and pathogenesis of periodontal disease, Periodonto 2001 (2000) 8-20.

[3] H.A. Schenkein, B.G. Loos, Inflammatory mechanisms linking periodontal diseases to cardiovascular diseases, J. Periodontol. 84 (2013) S51-S69.

[4] S.S. Socransky, A.D. Haffajee, M.A. Cugini, C. Smith, R.L. Kent Jr., Microbia complexes in subgingival plaque, J. Clin. Periodontol. 25 (1998) 134-144.

[5] P.J. Perez-Chaparro, C. Goncalves, L.C. Figueiredo, M. Faveri, E. Lobao, et al. Newly identified pathogens associated with periodontitis: a systematic review, J. Dent. Res. 93 (2014) 846-858.

[6] G. Hajishengallis, R.J. Lamont, Beyond the red complex and into more complexity: the polymicrobial synergy and dysbiosis (PSD) model of periodontal disease etiology, Mol. Oral Microbiol. 27 (2012) 409-419.

[7] M. Kebschull, R.T. Demmer, P.N. Papapanou, Gum bug, leave my heart alone!epidemiologic and mechanistic evidence linking periodontal infections and atherosclerosis, J. Dent. Res. 89 (2010) 879-902.

[8] P.B. Lockhart, A.F. Bolger, P.N. Papapanou, O. Osinbowale, M. Trevisan, et al. Periodontal disease and atherosclerotic vascular disease: does the evidence support an independent association?: a scientific statement from the American Heart Association, Circulation 22 (2012) 2520-2544.

[9] S.E. Epstein, J. Zhu, M.S. Burnett, Y.F. Zhou, G. Vercellotti, et al., Infection and atherosclerosis: potential roles of pathogen burden and molecular mimicry, Arterioscler. Thromb. Vasc. Biol. 20 (2000) 1417-1420.

[10] K. Buhlin, J. Holmer, A. Gustafsson, S. Hörkkö, A.G. Pockley, A. Johansson, et al. Association of periodontitis with persistent, pro-atherogenic antibody responses, J. Clin. Periodontol. 42 (2015) 1006-1014.

[11] R. Teles, C.Y. Wang, Mechanisms involved in the association between periodontal diseases and cardiovascular disease, Oral Dis. 17 (2011) 450-461.

[12] P.J. Pussinen, E. Könönen, S. Paju, K. Hyvärinen, U.K. Gursoy, et al., Periodonta pathogen carriage, rather than periodontitis, determines the serum antibody levels, J. Clin. Periodontol. 38 (2011) 405-411.

[13] C. Kudo, K. Naruishi, H. Maeda, Y. Abiko, T. Hino, M. Iwata, et al., Assessment of the plasma/serum IgG test to screen for periodontitis, J. Dent. Res. 91 (2012) 1190-1195.

[14] P.N. Papapanou, A.M. Neiderud, J. Sandros, G. Dahlen, Checkerboard assessments of serum antibodies to oral microbiota as surrogate markers of clinical periodontal status, J. Clin. Periodontol. 28 (2001) 103-106.

[15] J.M. Liljestrand, U.K. Gursoy, K. Hyvärinen, T. Sorsa, A.L. Suominen, et al, Combining salivary pathogen and serum antibody levels improves their diagnostic ability in detection of periodontitis, J. Periodontol. 85 (2013) $123-131$.

[16] J. Zhu, A.A. Quyyumi, J.E. Norman, G. Csako, M.A. Waclawiw, et al., Effects of total pathogen burden on coronary artery disease risk and C-reactive protein levels, Am. J. Cardiol. 15 (2000) 140-146.

[17] H.J. Rupprecht, S. Blankenberg C. Bickel, G. Rippin, G. Hafner, et al., Impact of viral and bacterial infectious burden on long-term prognosis in patients with coronary artery disease, Circulation 3 (2001) 25-31.

[18] F. Palm, P.J. Pussinen, A. Aigner, H. Becher, F. Buggle, et al., Association between infectious burden, socioeconomic status, and ischemic stroke Atherosclerosis 254 (2016) 117-123.

[19] S. Vaara, M.S. Nieminen, M.L. Lokki, M. Perola, P.J. Pussinen, et al., Cohort profile: the Corogene study, Int. J. Epidemiol. 41 (2012) 1265-1271.

[20] K. Buhlin, P. Mäntylä, S. Paju, J.S. Peltola, M.S. Nieminen, et al., Periodontitis is associated with angiographically verified coronary artery disease, J. Clin. Periodontol. 38 (2011) 1007-1014.

[21] A. Joss, R. Adler, N.P. Lang, Bleeding on probing. A parameter for monitoring periodontal conditions in clinical practice, J. Clin. Periodontol. 21 (1994) $402-408$.

[22] O. Lindy, K. Suomalainen, M. Mäkelä, S. Lindy, Statin use is associated with fewer periodontal lesions: a retrospective study, BMC Oral Health 15 (8) (2008) 16.

[23] J.M. Liljestrand, S. Paju, K. Buhlin, G.R. Persson, S. Sarna, et al., Lipopolysaccharide, a possible molecular mediator between periodontitis and coronary artery disease, J. Clin. Periodontol. (2017), https://doi.org/10.1111/jcpe.12751. Advance online publication.

[24] P. Mäntylä, K. Buhlin, S. Paju, G.R. Persson, M.S. Nieminen, et al., Subgingival Aggregatibacter actinomycetemcomitans associates with the risk of coronary artery disease, J. Clin. Periodontol. 40 (2013) 583-590.

[25] S.S. Socransky, A.D. Haffajee, C. Smith, L. Martin, J.A. Haffajee, et al., Use of checkerboard DNA-DNA hybridization to study complex microbial ecosystems, Oral Microbiol. Immunol. 19 (2004) 352-362.

[26] P. Pradhan-Palikhe, P. Mäntylä, S. Paju, K. Buhlin, G.R. Persson, et al., Subgingival bacterial burden in relation to clinical and radiographic periodontal parameters, J. Periodontol. 84 (2013) 1809-1817.

[27] P.J. Pussinen, T. Vilkuna-Rautiainen, G. Alfthan, K. Mattila, S. Asikainen, Multiserotype enzyme-linked immunosorbent assay as a diagnostic aid for periodontitis in large-scale studies, J. Clin. Microbiol. 40 (2002) 512-518.

[28] P.J. Pussinen, P. Jousilahti, G. Alfthan, T. Palosuo, S. Asikainen, et al., Antibodies to periodontal pathogens are associated with coronary heart disease, Arterioscler. Thromb. Vasc. Biol. 1 (2003) 1250-1254.

[29] PJ. Pussinen, E. Könönen, S. Paju, K. Hyvärinen, U.K. Gursoy, et al., Periodonta pathogen carriage, rather than periodontitis, determines the serum antibody levels, J. Clin. Periodontol. 38 (2011) 405-411.

[30] K. Hyvärinen, P. Mäntylä, K. Buhlin, S. Paju, M.S. Nieminen, et al., A common periodontal pathogen has an adverse association with both acute and stable coronary artery disease, Atherosclerosis 223 (2012) 478-484.

[31] J.M. Liljestrand, P. Mäntylä, S. Paju, K. Buhlin, K.A. Kopra, et al., Association of endodontic lesions with coronary artery disease, J. Dent. Res. 95 (2016) $1358-1365$.

[32] C. Vlachojannis, B.A. Dye, M. Herrera-Abreu, L. Pikdoken, J. Lerche-Sehm, et al., Determinants of serum IgG responses to periodontal bacteria in a nationally representative sample of US adults, J. Clin. Periodontol. 1 (2010) 685-696.

[33] A.J. Lusis, Atheroscler. Nat. 14 (2000) 233-241.

[34] P. Libby, A.H. Lichtman, G.K. Hansson, Immune effector mechanisms implicated in atherosclerosis: from mice to humans, Immunity 27 (38) (2013) 1092-1104.

[35] E.V. Kozarov, B.R. Dorn, C.E. Shelburne, W.A. Dunn Jr., A. Progulske-Fox, Human atherosclerotic plaque contains viable invasive Actinobacillus actinomycetemcomitans and Porphyromonas gingivalis, Arterioscler. Thromb. Vasc. Biol. 25 (2005) e17-e18.

[36] Y.W. Han, W. Houcken, B.G. Loos, H.A. Schenkein, M. Tezal, Periodontal disease, atherosclerosis, adverse pregnancy outcomes, and head-and-neck cancer, Adv. Dent. Res. 26 (2014) 47-55.

[37] S.P. Turunen, O. Kummu, K. Harila, M. Veneskoski, R. Soliymani, M. Baumann, et al., Recognition of Porphyromonas gingivalis gingipain epitopes by natural IgM binding to malondialdehyde modified low-density lipoprotein, PLoS One 7 (2012), e34910.

[38] C. Wang, J. Kankaanpää, O. Kummu, S.P. Turunen, R. Akhi, U. Bergmann, et al., Characterization of a natural mouse monoclonal antibody recognizing epitopes shared by oxidized low-density lipoprotein and chaperonin 60 of Aggregatibacter actinomycetemcomitans, Immunol. Res. 64 (2016) 699-710.

[39] J.D. Beck, P. Eke, G. Heiss, P. Madianos, D. Couper, D. Lin, et al., Periodontal disease and coronary heart disease: a reappraisal of the exposure, Circulation 5 (2005) 19-24.

[40] I.Z. Mustapha, S. Debrey, M. Oladubu, R. Ugarte, Markers of systemic bacterial exposure in periodontal disease and cardiovascular disease risk: a systematic review and meta-analysis, J. Periodontol. 78 (2007) 2289-2302.

[41] P.J. Pussinen, K. Nyyssönen, G. Alfthan, R. Salonen, J.A. Laukkanen, J.T. Salonen, Serum antibody levels to Actinobacillus actinomycetemcomitans predict the risk for coronary heart disease, Arterioscler. Thromb. Vasc. Biol. 25 (2005) 833-838.

[42] P.J. Pussinen, K. Tuomisto, P. Jousilahti, A.S. Havulinna, J. Sundvall, V. Salomaa, Endotoxemia, immune response to periodontal pathogens, and systemic inflammation associate with incident cardiovascular disease events, Arterioscler. Thromb. Vasc. Biol. 27 (2007) 1433-1439.

[43] P.J. Pussinen, G. Alfthan, J. Tuomilehto, S. Asikainen, P. Jousilahti, High serum antibody levels to Porphyromonas gingivalis predict myocardial infarction, Eur. J. Cardiovasc Prev. Rehabil. 11 (2004) 408-411.

[44] M.P. Cullinan, G.J. Seymour, Periodontal disease and systemic illness: will the evidence ever be enough? Periodontol 2013 (62) (2000) 271-286.

[45] J.D. Beck, P. Eke, D. Lin, P. Madianos, D. Couper, K. Moss, et al., Associations between IgG antibody to oral organisms and carotid intima-medial thickness in community-dwelling adults, Atherosclerosis 183 (2005) 342-348.

[46] L. Lund Håheim, I. Olsen, P. Nafstad, P. Schwarze, K.S. Rønningen, Antibody levels to single bacteria or in combination evaluated against myocardial infarction, J. Clin. Periodontol. 35 (2008) 473-478. 
[47] A. Boillot, H. Range, N. Danchin, S. Kotti, G. Cosler, et al., Periodontopathogens antibodies and major adverse events following an acute myocardial infarction: results from the French Registry of Acute ST-Elevation and Non-STElevation Myocardial Infarction (FAST-MI), J. Epidemiol. Community Health (2016), https://doi.org/10.1136/jech-2015-207043. Advance online publication.

[48] S.P. de Boer, J.M. Cheng, H. Range, H.M. Garcia-Garcia, J.H. Heo, et al., Antibodies to periodontal pathogens are associated with coronary plaque remodeling but not with vulnerability or burden, Atherosclerosis 237 (2014)
84-91.

49] P.N. Papapanou, A.M. Neiderud, A. Papadimitriou, J. Sandros, G. Dahlen, Checkerboard assessments of periodontal microbiota and serum antibody responses: a case-control study, J. Periodontol. 71 (2000) 885-897.

[50] G. Dahlen, W.M. Luan, U. Dahlgren, P.P. Papapanou, V. Baelum, O. Fejerskov, Subgingival bacterial clusters and serum antibody response as markers of extent and severity of periodontitis in adult Chinese, Eur. J. Oral Sci. 124 (2016) 179-187. 